\title{
BEBERAPA FAKTOR YANG BERHUBUNGAN DENGAN KEJADIAN HIPERURISEMIA PADA PASIEN RAWAT JALAN DI RS DUSTIRA CIMAHI
}

\author{
Nelly Olifa llyas, Fred Agung Suprihartono, Maryati Dewi \\ Program Studi D III Jurusan Gizi, Poltekkes Kemenkes Bandung \\ nelly_olifa@yahoo.com
}

\begin{abstract}
ABSTRAK
Hiperurisemia menjadi faktor independen terjadinya stroke dan penyakit kardiovaskuler. Cairan yang kurang menimbulkan terhambatnya ekskresi asam urat melalui urin sehingga menimbulkan hiperurisemia. Tujuan yang ingin dicapai pada penelitian ini secara umum adalah menganalisis besarnya risiko asupan cairan dan faktor determinan lain seperti kegemukan, asupan purin yang tinggi, asupan karbohidrat yang kurang, asupan lemak yang tinggi, riwayat keluarga dan aktifitas fisik pada kejadian hiperurisemia. Hasil penelitian diharapkan dapat menjadi bahan edukasi dalam memperbaiki pola makan dan pola minum agar terhindar dari penyakit gout (artritis). Penelitian ini menggunakan desain kasus kontrol tanpa matching dengan jumlah sampel 78 orang, 39 orang kasus dan 39 orang kontrol. Pengumpulan data dilakukan di RS Dustira Cimahi dengan usia sampel 30-60 tahun. Analisis data yang digunakan adalah analisis odds ratio dan analisis multivariat dengan uji stratifikasi. Kasus dalam penelitian ini adalah memiliki kadar asam urat darah lebih dari normal, tidak hamil, tidak menderita penyakit ginjal dan hipertensi grade II,. Kontrol memiliki kadar asam urat darah normal, tidak hipertensi grade II, tidak menderita sakit ginjal dan tidak hamil. Data yang dikumpulkan meliputi data umum, asupan cairan, asupan karbohidrat, asupan lemak total, antropometri, aktivitas fisik. Hasil penelitian menunjukkan bahwa asupan cairan yang kurang meningkatkan risiko 6,92 kali terkena hiperurisemia, asupan purin yang tinggi meningkatkan risiko 3,889 kali terkena hiperurisemia, asupan lemak yang tinggi meningkatkan risiko 3,383 kali terkena hiperurisemia, riwayat hiperurisemia dalam keluarga meningkatkan risiko 6,379 kali terkena hiperurisemia. Disarankan penderita hiperurisemia cukup mengasup cairan, memilih makanan sumber purin rendah, membatasi asupan makanan sumber lemak jenuh, penderita dengan riwayat keluarga hiperurisemia harus lebih berhati-hati dalam memilih makanan dan minuman sumber purin.
\end{abstract}

Kata kunci: faktor risiko, hiperurisemia, asupan cairan

\section{ABSTRACT}

\section{RISK FACTORS OF HYPERURECEMIA IN OUTPATIENTS IN DUSTIRA CIMAHI HOSPITAL}

Hyperuricemia is an independent factor to stroke and cardiovascular diseases. Low fluid intake prevents uric acid excretion through urine waste thus causing hyperuricemia. The aim of this research is to analyze the risk of fluid intake and other determinant factors of hyperuricemia. Outcome of this research can be used to educate people in relation to eating and drinking patternsfor preventing gout arthritis. This research used case control study design without matching, with 78 subjects (39 cases and 39 control). Control group had a normal uric acid concentration, no renal disease and no hypertention grade II, and not pregnant. While for case group, they had a higher uric acid concentration, no renal disease and no hypertention grade II, and not pregnant The data are taken at Dustira Hospital with the age range of 30 60 years old. Data taken are general data, fluid intake, carbohydrate intake, total fat intake, anthropometry, physical activities and family history of disease. Stastitical analysis used in this study was Odd Ratio (OR) and stratification analysis. The conclusion of this research is low intake of fluid has a risk of 6.92 times to be hyperuricemia, high intake of purin has a risk of 6.55 times to be hyperuricemia, high fat intake is 3,38 times and the history of hyperuricemia in family is 6.38 times risk to be hyperuricemia. High intake of purin and the history of hyperuricemia in the family were the confounding factors in the relationship between fluid intake and hyperuricemia. This research recommends that patients with hyperuricemia need adequate fluid intake, and need to lower their purin and fat intakes.

Keywords: risk factors, hyperuricemia, fluid intake 


\section{PENDAHULUAN}

$\mathrm{H}$ iperurisemia yang ditandai dengan tingginya kadar asam urat darah, merupakan faktor predisposisi penyakit gout dan faktor independen penyakit-penyakit degeneratif seperti stroke dan penyakit kardiovaskuler. ${ }^{1}$ Data prevalensi hiperurisemia di Indonesia belum didapati secara pasti.Prevalensi hiperurisemia di Bali ditemukan 18,2 persen. ${ }^{2}$ Studi di Thailand mendapatkan prevalensi hiperurisemia sebesar 10,6 persen dengan prevalensi 18,4 persen pada laki-laki dan 7,8 persen pada perempuan. ${ }^{3}$ Studi tentang hiperurisemia di China didapati prevalensi hiperurisemia di Qingdao China sebesar 25,3 persen pada usia 20-74 tahun dengan prevalensi 32,1 persen pada laki-laki dan 21,8 persen pada perempuan. ${ }^{4}$ Studi epidemiologik yang di lakukan di Bandungan, Jawa Tengah atas kerjasama WHO-COPCORD terhadap 4683 sampel berusia antara 15-45 tahun di dapatkan bahwa prevalensi hiperurisemia sebesar 24,3 persen pada laki-laki dan 11,7 persen pada wanita. ${ }^{5}$

Kadar asam urat darah yang meningkat dapat terjadi secara primer dan sekunder. Penyebab primer hiperurisemia adalah kelainan molekuler yang masih belum bisa dijelaskan. Penyebab sekunder hiperurisemia adalah undersecretion dan overproduction asam urat. ${ }^{5}$ Jenis kelamin dan usia merupakan faktor risiko hiperurisemia yang tidak dapat diubah. ${ }^{6}$ Dehidrasi karena asupan cairan yang kurang menjadi salah satu faktor risiko hiperurisemia terkait penurunan ekskresi asam urat melalui ginjal. ${ }^{6}$ Dehidrasi terjadi jika asupan cairan seseorang tidak sesuai dengan kebutuhan. Asupan cairan sangat penting diperhatikan mengingat sebagian besar komposisi tubuh manusia terdiri atas cairan. ${ }^{7}$

Faktor risiko peningkatan produksi asam urat lainyang dapat diubah adalah konsumsi makanan tinggi lemak total, tinggi purin, tinggi fruktosa, obesitas, obat-obatan dan beberapa penyakit kelainan ginjal. ${ }^{6}$ Lyu et al. mendapati bahwa faktor diet dan obesitas merupakan faktor risiko terjadinya peningkatan kadar asam urat sementara penelitian Hensen \& Putra menemukan bahwa asupan purin dan obesitas berhubungan dengan hiperurisemia. ${ }^{2}$

Sejauh ini edukasi bagi penderita hiperurisemia masih tetap ditekankan kepada pembatasan jumlah asupan purin tidak kepada jenis makanan tertentu. ${ }^{8}$ Faktor diet dan asupan cairan merupakan faktor risiko hiperurisemia yang dapat diubah, sehingga merupakan faktor penting dalam edukasi sebagai upaya pencegahan dan penatalaksanaan hiperurisemia. Besarnya hubungan asupan cairan dengan risiko hiperurisemia masih belum banyak dipelajari, sedangkan hubungan faktor diet yang meliputi asupan lemak total, asupan purin, asupan karbohidrat, status gizi dan aktifitas fisik sebagai faktor risiko hiperurisemia masih belum konsisten.

Tujuan dari penelitian ini adalah mempelajari hubungan factor determinan hiperurisemia sebagai faktor risiko pada kejadian hiperurisemia dengan mengidentifikasi faktor determinan hiperurisemia, resiko asupan cairan, resiko asupan lemak total, resiko asupan karbohidrat, resiko konsumsi sumber purin, resiko kegemukan, resiko aktifitas fisik.

\section{METODE PENELITIAN}

Penelitian ini menggunakan desain case control tanpa matching. Pengumpulan data dilaksanakan di Poliklinik rawat jalan penyakit dalam RSAD.Dustira Kota Cimahi pada bulan Mei - Agustus 2013. Besar sampel minimal yang dibutuhkan sejumlah 78 orang dengan masing-masing kelompok kasus dan control 39 orang. Sampel diambil secara consecutive sampling dengan criteria inklusi kasus sebagai berikut:berusia 30-60 tahun, memiliki kadar asam urat darah $>7 \mathrm{mg} / \mathrm{dL}$ bagi laki-laki dan > $6 \mathrm{mg} / \mathrm{dL}$ bagi perempuan sampel menjadi 40 sampel per kelompok sehingga total sampel menjadi sebesar 80 anak, yang terdiri dari 40 kasus dan 40 kontrol, tidak menderita penyakit gagal ginjal dan hipertensi grade 2, tidak sedang hamil, bersedia menjadi sampel penelitian. Kriteria inklusi control adalah memiliki kadar asam urat darah yang normal, tidak menderita penyakit gagal ginjal dan hipertensi grade 2, tidak sedang hamil, bersedia menjadi sampel penelitian.

Data yang dikumpulkan dari sampel adalah hasil pemeriksaan asam urat darah, identitas sampel, data antropometri tinggi dan berat badan, asupan cairan, asupan karbohidrat, asupan lemak total, riwayat penyakit dan riwayat hiperurisemia, asupan sumber purin, aktifitas fisik. Sampel termasuk hiperurisemia 
jika kadar asam urat darah dinyatakan $>7$ $\mathrm{mg} / \mathrm{dL}$ bagi laki-laki dan $>6 \mathrm{mg} / \mathrm{dL}$ bagi perempuan dan tidak hiperurisemia, jika kadar asam urat darah dinyatakan $<7 \mathrm{mg} / \mathrm{dL}$ bagi laki-laki dan > $6 \mathrm{mg} / \mathrm{dL}$ bagi perempuan. Asupan cairan dikatakan kurang bila $<1400$ $\mathrm{ml} /$ hari dan baik bila asupan cairan $\geq 1400$ $\mathrm{ml} /$ hari, yang berasal dari minuman yang dikonsumsi sehari. Dikumpulkan menggunakan kuesioner dengan alat bantu foto gelas yang digunakan untuk minum. Asupan karbohidrat dikatakan baik, bila gram asupan karbohidrat memenuhi $50-75 \%$ kebutuhan energi dan dikatakan kurang baik, bila gram asupan karbohidrat $<50 \%$ kebutuhan energi. Asupan lemak total baik, bila gram asupan lemak total memenuhi $20-25 \%$ kebutuhan energi dan kurang baik, bila gram asupan lemak total> 25\% kebutuhan energi. Asupan purin tinggi, jika skor konsumsi bahan makanan sumber purin $\geq$ nilai mean $(128,3)$ dan rendah jika skor konsumsi bahan makanan sumber purin < nilai mean $(128,3)$. Data asupan karbohidrat, lemak, purin, dikumpulkan menggunakan kuesioner SQFFQ. Sampel dikatakan gemuk jika IMT $>25$ dan normal jika IMT $\leq 25$.Aktifitas fisik diukur menggunakan IPAQ, dikategorikan menjadi aktifitas kurang jika kebutuhan energi untuk aktifitas fisik < 600 METS-menit/minggu dan cukup jika kebutuhan energi untuk aktifitas fisik $\geq 600$ METS-menit/minggu. Riwayat hiperurisemia dalam keluarga dikategorikan menjadi ada dan tidak.Hipotesis penelitian ditetapkan adalah asupan cairan yang kurang, asupan lemak total yang tinggi, asupan karbohidrat yang rendah, asupan sumber purin yang tinggi, aktifitas fisik yang kurang, kegemukan, riwayat hiperurisemia meningkatkan risiko hiperurisemia.

Analisis data menggunakan uji odds ratio untuk melihat besarnya risiko antara variabel paparan dan efek. Analisis multivariat menggunakan uji stratifikasi untuk menganalisa pengaruh variabel yang diduga sebagai variable perancu (confounding). Analisa stratifikasi akan dilakukan jika hasil perhitungan OR menunjukkan bahwa asupan cairan merupakan faktor risiko kejadian hiperurisemia. Variabel yang diduga sebagai perancu akan memenuhi syarat sebagai perancu jika beda adjusted odd ratio $(a O R)$ dan crude odd ratio $(c O R)>10 \%$.

\section{HASIL}

Jumlah sampel yang dikumpulkan pada penelitian ini adalah 78 orang dengan 39 orang kasus dan 39 orang kontrol. Data Karakteristik sampel yang dikumpulkan adalah umur, jenis kelamin, pendidikan dan pekerjaan terangkum dalam Tabel 1.

Berdasarkan usia, tidak terdapat perbedaan antara kasus dan kontrol. Pada kategori usia $\geq 55$ tahun didapati 64,1 persen pada kelompok kasus dan 69,2 persen pada kelompok kontrol. Secara keseluruhan umur rata-rata sampel 56 tahun, dengan umur termuda 39 tahun dan tertua 68 tahun.

Tabel 1

Distribusi Sampel menurut Karakteristik

\begin{tabular}{lllccc}
\hline \multirow{2}{*}{ Karakteristik } & \multicolumn{1}{c}{ Kategori } & \multicolumn{2}{c}{ Kasus $(\mathbf{n}=39)$} & \multicolumn{2}{c}{ Kontrol $(\mathbf{n}=39)$} \\
\cline { 3 - 6 } Umur & $\geq 55$ tahun & 25 & 64,1 & 27 & 69,2 \\
& $<55$ tahun & 14 & 35,9 & 12 & 30,8 \\
\multirow{3}{*}{ Jenis kelamin } & & & & & \\
& Laki-laki & 17 & 43,6 & 14 & 35,9 \\
\multirow{3}{*}{ Pendidikan } & Perempuan & 22 & 56,4 & 25 & 64,1 \\
\multirow{3}{*}{ Pekerjaan } & Dasar & 22 & 56,4 & 21 & 53,8 \\
& Lanjut & 17 & 43,6 & 18 & 46,2 \\
& Tidak bekerja & 25 & 64,1 & 29 & 69,2 \\
& Bekerja & 14 & 35,9 & 10 & 30,8 \\
\hline
\end{tabular}


Tabel 2

Distribusi Sampel menurut Kategori Asupan Cairan

\begin{tabular}{llccc}
\hline & \multicolumn{2}{l}{ Kasus $(\boldsymbol{n}=39)$} & \multicolumn{2}{c}{ Kontrol $(\boldsymbol{n}=39)$} \\
\cline { 2 - 5 } Asupan Cairan & $\mathbf{n}$ & $\%$ & $\mathbf{n}$ & $\%$ \\
\hline Kurang & 25 & 64,1 & 8 & 20,5 \\
Cukup & 14 & 35,9 & 31 & 79,5 \\
\hline
\end{tabular}

Tabel 3

Distribusi Sampel menurut Faktor Risiko Hiperurisemia

\begin{tabular}{llcccc}
\hline \multirow{2}{*}{ Faktor Risiko } & \multirow{2}{*}{ Kategori } & \multicolumn{2}{c}{ Kasus $(\mathbf{n}=39)$} & \multicolumn{2}{c}{ Kontrol $(\mathbf{n}=39)$} \\
\cline { 2 - 6 } & & $\mathbf{n}$ & $\%$ & $\mathbf{n}$ & $\%$ \\
\hline Asupan karbohidrat & - Kurang & 39 & 100 & 36 & 92.3 \\
& - Cukup & 0 & 0 & 3 & 7.7 \\
\hline Asupan lemak total & - Tinggi & 21 & 53,8 & 10 & 25,6 \\
& - Rendah & 18 & 46,2 & 29 & 74,4 \\
\hline Asupan Purin & - Tinggi & 21 & 53,8 & 9 & 23,1 \\
& - Rendah & 18 & 46,2 & 30 & 76,9 \\
\hline Aktivitas fisik & - Kurang & 8 & 20.5 & 11 & 28,2 \\
& - Cukup & 31 & 79.5 & 28 & 71,8 \\
\hline Kegemukan & - Gemuk & 17 & 43,6 & 22 & 56,4 \\
& - Normal & 22 & 56,4 & 17 & 43,6 \\
\hline Riwayat Hiperurisemia & - Ya & 37 & 94,9 & 29 & 84,6 \\
& - Tidak & 2 & 5,1 & 10 & 15,4 \\
\hline
\end{tabular}

Hasil penelitian menemukan bahwa proporsi sampel laki-laki pada kelompok kasus hampir sama dengan kelompok kontrol yaitu 43,6 persen pada kasus dan 35,9 persen pada kontrol. Proporsi antara kasus dan kontrol pada tingkat pendidikan tidak jauh berbeda, dimana pendidikan dasar pada kasus 56,4 persen sedangkan pada kontrol 53,8 persen.

Hasil penelitian didapatkan bahwa proporsi sampel yang tidak bekerja lebih tinggi pada kasus dibandingkan pada kelompok kontrol yaitu 74,4 persen dibandingkan 64,1 persen. Penelitian ini sejalan dengan hasil penelitian llyas dan Isdiany (2006) yang melaporkan bahwa sampel tidak bekerja sebanyak 84 persen. Jadi aktivitas sampel yang rendah mengakibatkan pengeluaran energi yang sedikit, sehingga terjadi penimbunan lemak di tubuh, yang akan mempengaruhi metabolisme asam urat di darah. ${ }^{9}$

Dari Tabel 2 dapat diketahui proporsi asupan cairan dengan kategori kurang ditemukan lebih besar pada kelompok kasus $(64,1 \%)$ daripada kelompok kontrol $(20,5 \%)$. Rata-rata sampel mengasup cairan 1455,89 ml setiap hari, dengan asupan terendah sebesar $500 \mathrm{ml}$ dan tertinggi $3.100 \mathrm{ml}$ per hari.

Berdasarkan Tabel. 3 diketahui bahwa proporsi asupan karbohidrat yang kurang baik pada kasus dan kontrol tidak jauh berbeda. Pada kasus ditemukan 100 persen memiliki asupan karbohidrat yang kurang, dan pada kontrol 92,3 persen. Secara keseluruhan, asupan karbohidrat rata-rata sampel sebesar 144,09 gram, dengan asupan terendah 54,4 gram dan tertinggi 294,3 gram.

Proporsi asupan lemak yang tinggi lebih besar ditemui pada kelompok kasus dibandingkan kelompok kontrol yaitu 53,8 persen dan 25,6 persen. Rerata asupan lemak sampel sebesar 60,02 gram, dengan asupan terendah 26,6 dan tertinggi 162,9 gram.

Berdasarkan asupan makanan sumber purin yang tinggi, kelompok kasus memiliki proporsi lebih besar daripada kelompok kontrol yaitu 53,8 persen dan 23,1 persen. Rerata asupan purin diketahui sebesar $128,31 \mathrm{mg}$, dengan asupan terendah 21,38 dan tertinggi $1.140,54 \mathrm{mg}$. Hasil penelitian ini sesuai dengan penelitian Wulandari, A (2013) dilaporkan bahwa asupan purin pada kasus tinggi yaitu 50 
persen. ${ }^{10}$ Pada penelitian llyas, N (2006) didapatkan pula sampel sebanyak 43 persen mengonsumsi purin yang tinggi yang banyak dikonsumsi jenis mengandung purin sedang dan tinggi: kaldu, gulai, kacang-kacangan. ${ }^{9}$

Berdasarkan Tabel 3 diketahui bahwa antara kasus dan kontrol sebagian besar sampel yang aktivitas nya kurang ada pada kelompok kontrol yaitu 28,2 persen dibandingkan 20,5 persen. Rerata aktivitas fisik tercatat sebesar 1.154,8 METS. Dengan pencapaian terendah 198 METS dan tertinggi 5.595 METS.Pada penelitian ini banyak sampel $(52,5 \%)$ yang berumur di atas 55 tahun dan 52,5 persen sampel sudah tidak bekerja lagi.

Hasil penelitian ini didapatkan sampel kontrol banyak yang gemuk dibandingkan dengan kasus. Pada kelompok kontrol proporsi yang gemuk ditemukan 56,4 persen sementara pada kelompok kasus 43,6 persen. Rerata IMT sampel sebesar 25,39 kg/m2, dengan IMT terendah $16,17 \mathrm{~kg} / \mathrm{m} 2$ dan tertinggi $37,8 \mathrm{~kg} / \mathrm{m} 2$.

Berdasarkan riwayat hiperurisemia, hasil penelitian menunjukkan bahwa pada kelompok kasus dan kontrol sebagian besar memiliki riwayat hiperurisemia. Meskipun demikian, proporsi riwayat hiperurisemia ditemukan lebih besar pada kelompok kasus yaitu sebanyak 94,9 persen sedangkan pada kelompok kontrol 74,4 persen.

Hasil pengujian statistik hubungan asupan cairan dan risiko hiperurisemia didapat hasil yang signifikan. Sampel dengan asupan cairan kurang berisiko 6,9 kali mengalami hiperurisemia dibandingkan dengan sampel yang asupan cairannya cukup (Tabel 4). Hasil penelitian ini tidak sejalan dengan penelitian Diantari dan Candra (2013) yang mendapatkan hubungan yang tidak bermakna pada asupan cairan dan hiperurisemia. ${ }^{11}$

Tabel 4

Distribusi Sampel menurut Kategori Asupan Cairan dan Risiko Kejadian Hiperurisemia

\begin{tabular}{|c|c|c|c|c|c|c|c|c|}
\hline \multirow{2}{*}{ Asupan Cairan } & \multicolumn{2}{|c|}{$\begin{array}{l}\text { Kasus } \\
(n=39)\end{array}$} & \multicolumn{2}{|c|}{$\begin{array}{l}\text { Kontrol } \\
(n=39)\end{array}$} & \multirow{2}{*}{ OR } & \multicolumn{2}{|c|}{$95 \% \mathrm{Cl}$} & \multirow[b]{2}{*}{$p$} \\
\hline & $n$ & $\%$ & $n$ & $\%$ & & Lower & Upper & \\
\hline Kurang & 25 & 64,1 & 8 & 20,5 & \multirow{2}{*}{6,920} & \multirow{2}{*}{2,505} & \multirow{2}{*}{19,112} & \multirow{2}{*}{0,00} \\
\hline Cukup & 14 & 35,9 & 31 & 79,5 & & & & \\
\hline
\end{tabular}

Tabel 5

Distribusi Sampel menurut Faktor Risiko Lain dan Kejadian Hiperurisemia

\begin{tabular}{|c|c|c|c|c|c|c|c|c|c|}
\hline \multirow{2}{*}{ Faktor Risiko } & \multirow{2}{*}{ Kategori } & \multicolumn{2}{|c|}{$\begin{array}{l}\text { Kasus } \\
(n=39)\end{array}$} & \multicolumn{2}{|c|}{$\begin{array}{l}\text { Kontrol } \\
(n=39)\end{array}$} & \multirow{2}{*}{ OR } & \multicolumn{2}{|c|}{$95 \% \mathrm{Cl}$} & \multirow[b]{2}{*}{$p$} \\
\hline & & $n$ & $\%$ & $n$ & $\%$ & & Lower & Upper & \\
\hline \multirow[t]{2}{*}{ Asupan karbohidrat } & Kurang & 39 & 100 & 36 & 92.3 & - & - & - & 0,239 \\
\hline & Cukup & 0 & 0,0 & 3 & 7.7 & & & & \\
\hline \multirow[t]{2}{*}{ Asupan lemak total } & Tinggi & 21 & 53,8 & 10 & 25,6 & 3,38 & 1,30 & 8,79 & 0,021 \\
\hline & Rendah & 18 & 46,2 & 29 & 74,4 & & & & \\
\hline \multirow[t]{2}{*}{ Asupan Purin } & Tinggi & 21 & 53,8 & 9 & 23,1 & 3,89 & 1,47 & 10,31 & 0,010 \\
\hline & Rendah & 18 & 46,2 & 30 & 76,9 & & & & \\
\hline \multirow[t]{2}{*}{ Aktivitas fisik } & Kurang & 8 & 20.5 & 11 & 28,2 & 0,66 & 0,23 & 1,87 & 0,599 \\
\hline & Cukup & 31 & 79.5 & 28 & 71,8 & & & & \\
\hline \multirow[t]{2}{*}{ Kegemukan } & Gemuk & 17 & 43,6 & 22 & 56,4 & 0,59 & 0,24 & 1,46 & 0,365 \\
\hline & Normal & 22 & 56,4 & 17 & 43,6 & & & & \\
\hline \multirow[t]{2}{*}{ Riwayat Hiperurisemia } & Ya & 37 & 94,9 & 29 & 84,6 & 6,38 & 1,29 & 31,4 & 0,028 \\
\hline & Tidak & 2 & 5,1 & 10 & 15,4 & & & & \\
\hline
\end{tabular}


Besaran risiko (OR) asupan karbohidrat yang kurang tidak dapat dianalisa karena data asupan dengan kategori cukup sebesar 0 persen, dengan nlai $p>0,05$, artinya secara statistik hubungan kedua variabel tidak bermakna. Hasil penelitian ini menunjukkan bahwa sebagian besar sampel kasus $(100 \%)$ dan kontrol (92.3\%) memiliki asupan karbohidrat yang kurang yaitu < 50-75\% kebutuhan energi.Hasil penelitian yang sejalan juga ditemui pada penelitian Budianti (2008).

Berdasarkan data pada Tabel 5 terlihat bahwa asupan lemak, asupan purin,dan riwayat hiperurisemia yang memiliki hasil uji statistik yang bermakna terhadap hiperurisemia. Sampel dengan asupan lemak tinggi memiliki risiko 3.38 kali mengalami hiperurisemia daripada sampel dengan asupan lemak rendah. Sementara, sampel dengan asupan purin tinggi memiliki risiko 3,89 kali mengalami hiperurisemia daripada sampel dengan asupan purin yang rendah. Riwayat hiperurisemia yang pernah diderita anggota keluarga menjadi faktor risiko 6,38 kali pada kelompok yang pernah menderita hiperurisemia, dibandingkan pada kelompok yang tidak pernah. Berbeda dengan hasil penelitian Budianti (2008), yang menunjukkan tidak ada pengaruh penyakit lain, yaitu hiperkolesterol dan diabetes mellitus terhadap hiperurisemia dan gout. ${ }^{12}$

Hasil uji statistik menunjukkan bahwa tidak terdapat hubungan yang bermakna antara aktifitas fisik dan hiperurisemia $(p=0,66)$. Hasil yang sama didapatkan pula pada uji statistik hubungan kegemukan terhadap kejadian hiperurisemia. Penelitian yang dilakukan oleh
Hensen (2008) mendapatkan hasil yang bermakna antara kegemukan dan

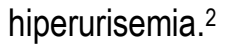

Tabel 6 menjelaskan bahwa riwayat hiperurisemia berpengaruh pada strata pertama asupan cairan, hubungannya dengan kejadian hiperurisemia, dengan risiko sebesar 6,55 kali. Artinya, pada strata pertama asupan cairan, risiko kejadian hiperurisemia karena pengaruh riwayat hiperurisema 6,55 kali lebih besar terjadi pada asupan cairan yang kurang dibandingkan pada asupan cairan yang cukup, pada $\mathrm{Cl} 95 \%$ $(1,92-23,23)$. Pada kelompok kedua, riwayat hiperurisemia keluarga tidak berpengaruh pada hubungan asupan cairan dan kejadian hiperurisemia.

Asupan purin yang tinggi berpengaruh pada strata pertama asupan cairan, hubungannya dengan kejadian hiperurisemia, dengan risiko sebesar 11,94 kali. Artinya, pada strata pertama asupan cairan, risiko kejadian hiperurisemia karena pengaruh asupan purin yang tinggi sebesar 11,94 kali lebih besar terjadi pada asupan cairan yang kurang dibandingkan pada asupan cairan yang cukup, pada $\mathrm{Cl}$ 95\% (1,22 620). Pada kelompok kedua, pengaruh asupan purin tinggi pada risiko kejadian hiperurisemia 6,57 kali lebih besar terjadi pada asupan cairan yang kurang. Secara statistik pengaruhnya bermakna, pada CI 95\% (1,51 - 30,60). Analisa lebih lanjut menunjukan bahwa asupan purin yang tinggi merupakan faktor perancu pada hubungan antara asupan cairan dan kejadian Hiperurisemi, dengan beda $\mathrm{COR}$ dan aOR = 16,6 \% (Tabel 7).

Tabel 6

Pengaruh Riwayat Hiperurisemia Keluarga pada Hubungan antara Asupan Cairan dan Kejadian Hiperurisemia

\begin{tabular}{|c|c|c|c|c|}
\hline \multirow{3}{*}{ Kejadian Hiperurisemia } & \multirow{2}{*}{\multicolumn{2}{|c|}{$\frac{\text { Riwayat Penyakit Keluarga }}{\text { Asupan Cairan }}$}} & \multirow{2}{*}{\multicolumn{2}{|c|}{$\frac{\text { Riwayat Penyakit Keluarga }}{\text { Asupan Cairan }}$}} \\
\hline & & & & \\
\hline & Kurang & Cukup & Kurang & Cukup \\
\hline Kasus & 25 & 12 & 0 & 2 \\
\hline Kontrol & 7 & 22 & 1 & 9 \\
\hline OR & \multirow{2}{*}{\multicolumn{2}{|c|}{$\begin{array}{c}6,55 \\
1,92-23,23\end{array}$}} & \multirow{2}{*}{\multicolumn{2}{|c|}{$\begin{array}{c}0,0 \\
0,00-158,2\end{array}$}} \\
\hline $95 \% \mathrm{Cl}$ & & & & \\
\hline $\mathrm{aOR}$ & \multicolumn{4}{|c|}{$5,79(2,04-16,46)$} \\
\hline $\mathrm{COR}$ & \multicolumn{4}{|c|}{$6,92(2,23-22,18)$} \\
\hline Beda aOR - cOR & \multicolumn{4}{|c|}{$16,32 \%$} \\
\hline
\end{tabular}


Tabel 7

Pengaruh Asupan Purin terhadap Hubungan Antara Asupan Cairan dan Kejadian Hiperurisemia

\begin{tabular}{|c|c|c|c|c|}
\hline \multirow{3}{*}{ Kejadian Hiperurisemia } & \multicolumn{2}{|c|}{ Asupan Purin } & \multicolumn{2}{|c|}{ Asupan Purin } \\
\hline & \multicolumn{2}{|c|}{ Asupan Cairan } & \multicolumn{2}{|c|}{ Asupan Cairan } \\
\hline & Kurang & Cukup & Kurang & Cukup \\
\hline Kasus & 12 & 6 & 12 & 6 \\
\hline Kontrol & 7 & 23 & 7 & 23 \\
\hline OR & \multirow{2}{*}{\multicolumn{2}{|c|}{$\begin{array}{c}11,94 \\
1,22-620\end{array}$}} & \multirow{2}{*}{\multicolumn{2}{|c|}{$\begin{array}{c}6,57 \\
1,51-30,60\end{array}$}} \\
\hline $95 \% \mathrm{Cl}$ & & & & \\
\hline $\mathrm{aOR}$ & \multicolumn{4}{|c|}{$8,07(2,65-24,60)$} \\
\hline cOR & \multicolumn{4}{|c|}{$6,92(2,23-22,18)$} \\
\hline Beda aOR - cOR & \multicolumn{4}{|c|}{$16,6 \%$} \\
\hline
\end{tabular}

Tabel 8

Pengaruh Asupan Lemak terhadap Hubungan antara Asupan Cairan dan Kejadian Hiperurisemia

\begin{tabular}{|c|c|c|c|c|}
\hline \multirow{3}{*}{ Kejadian Hiperurisemia } & \multicolumn{2}{|c|}{ Asupan Lemak } & \multicolumn{2}{|c|}{ Asupan Lemak } \\
\hline & \multicolumn{2}{|c|}{ Asupan Cairan } & \multicolumn{2}{|c|}{ Asupan Cairan } \\
\hline & Kurang & Cukup & Kurang & Cukup \\
\hline Kasus & 14 & 7 & 11 & 7 \\
\hline Kontrol & 1 & 9 & 7 & 22 \\
\hline OR & \multirow{2}{*}{\multicolumn{2}{|c|}{$\begin{array}{c}18 \\
1,61-471,87\end{array}$}} & \multirow{2}{*}{\multicolumn{2}{|c|}{$\begin{array}{c}4,94 \\
1,16-22,22\end{array}$}} \\
\hline $95 \% \mathrm{Cl}$ & & & & \\
\hline $\mathrm{aOR}$ & \multicolumn{4}{|c|}{$7,26(2,47-21,35)$} \\
\hline cOR & \multicolumn{4}{|c|}{$6,92(2,23-22,18)$} \\
\hline Beda aOR - cOR & \multicolumn{4}{|c|}{$4,9 \%$} \\
\hline
\end{tabular}

Asupan lemak berpengaruh pada strata pertama asupan cairan, hubungannya dengan kejadian hiperurisemia, dengan risiko sebesar 18,00 kali. Artinya, pada strata pertama asupan cairan, risiko kejadian hiperurisemia karena pengaruh asupan lemak sebesar 18,00 kali lebih besar terjadi pada asupan cairan yang kurang dibandingkan pada asupan cairan yang cukup, pada Cl 95\% (1,61 - 471,87). Pada kelompok kedua, pengaruh asupan lemak pada risiko kejadian hiperurisemia 4,94 kali lebih besar terjadi pada asupan cairan yang kurang. Secara statistik pengaruhnya bermakna, pada $\mathrm{Cl} 95 \%(1,16-22,22)$. Analisa lebih lanjut menunjukan bahwa asupan lemakbukan merupakan faktor perancu pada hubungan antara Asupan Cairan dan kejadian Hiperurisemi, dengan beda $\mathrm{COR}$ dan $\mathrm{aOR}=4,9$ $\%$, atau dengan kata lain pada analisa tersebut kejadian hiperurisemia benar-benar karena pengaruh asupan lemak yang tinggi, tanpa dipengaruhi asupan cairan (Tabel. 8).

\section{BAHASAN}

Johnson RJ (2003) mengatakan kadar asam urat akan meningkat sekitar 10 persen antara usia 20 - 60 tahun. ${ }^{13}$ Hasil penelitian ini tidak sesuai dengan teori yang ada karena lebih banyak usia $>55$ tahun terjadi pada kontrol dibandingkan pada kasus. Namun sejalan dengan penelitian $\mathrm{Li}$ - Ching Lyu, dkk di Taiwan (2003) menyatakan bahwa golongan usia $\geq 40$ tahun kadar asam uratnya lebih tinggi banyak terdapat pada kontrol bila dibandingkan dengan kasus. ${ }^{14}$ Ada keterbatasan pada penentuan pemilihan umur, menurut teori yang berpotensi menderita hyperurisemia adalah umur yang lebih dari 40 tahun, tetapi peneliti juga mengambil umur lebih muda yaitu 30 tahun 
karena semua yang umur lebih tua sudah mencukupi untuk jadi sampel.

Asupan cairan yang cukup membantu membuang produk akhir metabolisme melalui ginjal. Cairan dapat membantu ginjal dalam metabolisme asam urat untuk diekskresikan dan direabsorpsi. ${ }^{15,16}$ Asupan cairan merupakan salah satu faktor risiko hiperurisemia.

Penelitian ini tidak sejalan hasilnya dengan penelitian Hensen (2007) di Bali didapatkan asupan cairan yang kurang tidak berdampak terhadap kadar asam urat di darah (Hyperurisemia). ${ }^{2}$ Ada keterbatasan pada asupan cairan diantaranya asupan yang digali dari sampel hanya berasal dari cairan yang diminum (air putih, jus, kopi, teh dan air isotonic). Sementara cairan yang berasal dari bahan makanan dan makanan seperti sayur dan buah-buahan tidak diambil. Menurut Guyton (1993) air yang berasal dari makanan yang sudah diteliti menghasilkan $870 \mathrm{ml}$ dan dari metabolisme tubuh $350 \mathrm{ml}$. Dengan demikian asupan air dari minum cukup1000 ml. ${ }^{17}$

Antisipasi untuk kerkurangan cairan dari makanan peneliti menetapkan batasan air dari asupan minuman yang baik adalah $1400 \mathrm{ml} /$ hari. Keterbatasan yang lain untuk menentukan jumlah cairan yang diasup sulit juga karena besar gelas yang dipersepsikan sampel belum tentu sama dengan peneliti. Dalam mencegah terjadinya bias maka dilakukan dengan memperlihatkan kepada sampel foto macammacam gelas yang berisi air yang telah ditentukan volume air pada gelas tersebut. Penelitian ini sejalan dengan hasil penelitian Aldona (2013) melaporkan bahwa asupan cairan yang kurang pada penderita hiperurisemia sebesar 61,76 persen. ${ }^{10}$ Asupan yang kurang ini dapat meningkatkan asam urat di darah, asupan cairan yang lebih 3 liter/hari dapat mendorong pengeluaran asam urat dan batu ginjal yang terbentuk karena tinggi asam urat di ginjal (KRANSES 2004). ${ }^{18}$

Hiperurisemia tidak hanya dipengaruhi asupan, tetapi oleh banyak faktor yaitu status gizi, obesitas, asupan purin, penyakit ginjal kronik. ${ }^{2}$ Terkait hiperurisemia, cairan berperan dalam proses ekskresi sisa metabolisme purin dan mengurangi saturasi urin sehingga sisa metabolisme purin dapat dikeluarkan dari tubuh. Asupan cairan yang kurang dapat menimbulkan dehidrasi. 16,19 Dehidrasi menjadi faktor risiko hiperurisemia karena menurunkan ekskresi asam urat. $^{6}$ Sejalan dengan teori, hasil penelitian menunjukkan hal yang sama yaitu sampel dengan asupan cairan kurang lebih berisiko hiperurisemia dibandingkan dengan sampel yang asupan cairannya cukup. Kebutuhan cairan seseorang salah satunya dipengaruhi oleh usia. Sampel penelitian ini, baik pada kasus dan kontrol sebagian besar berusia $\geq 55$ tahun. Namun demikian, 64,1 persen sampel kasus memiliki asupan cairan kurang, sementara hanya 20,5 persen sampel kontrol yang memiliki asupan cairan kurang. Asupan karbohidrat berhubungan dengan proses pembuangan asam urat melalui urin. Konsumsi jenis karbohidrat yang dianjurkan agar pembuangan asam urat lancar adalah karbohidrat kompleks dan sangat dibatasi konsumsi karbohidrat sederhana.

Hiperurisemia pada kegemukan terjadi karena adanya resistensi insulin sehingga asam urat akan lebih banyak dihasilkan pada orang gemuk dibanding orang kurus. jumlah sampel kasus dan control dengan kategori gemuk dan normal proporsinya hampir sebanding. Kurang aktivitas berpotensi kelebihan berat badan dan terjadi penumpukan lemak, baik pada laki-laki maupun perempuan. Menurut Hadian (2008) kurangnya aktivitas fisik adalah penyebab terjadinya obesitas sehingga akan menurunkan ekskresi asam urat karena kelebihan lemak di tubuh. ${ }^{20}$ Aktifitas fisik seringkali dikaitkan dengan kegemukan. Aktifitas fisik juga diduga sebagai faktor yang dapat meningkatkan kadar asam urat darah karena produksi asam laktat selama beraktifitas terutama aktifitas fisik yang berat. Aktifitas fisik merupakan salah satu faktor yang mempengaruhi asupan cairan seseorang. Sampel kasus dengan aktifitas kurang (100\%) memiliki asupan cairan yang kurang, pada kontrol hanya 9 persen yang asupan cairannya kurang. Sampel kasus dengan aktivitas cukup, 45 persen memiliki asupan cairan yang cukup sedangkan pada sampel kontrol 75.9 persen memiliki asupan cairan yang cukup. Dengan demikian asupan karbohidrat tinggi, aktivitas kurang akan berakibat status gizi menjadi gemuk. Dengan gemuk, lemak tubuh akan meningkat dan akan menghambat metabolisme purin (asam urat).

Asam urat merupakan hasil akhir metabolisme purin, salah satu komponen asam nukleat yang terdapat dalam inti sel. Berbagai penelitian diantaranya Diantari dan Candra 
(2013) ${ }^{11}$, Hensen $(2007)^{2}$ mendapatkan hasil penelitian bahwa asupan purin berhubungan signifikan dengan hiperurisemia. Pada sampel kasus dengan usia $\geq 55$ tahun, persentase sampel dengan asupan purin yang tinggi $(53,8 \%)$ dan rendah $(46,2 \%)$. Sedangkan pada sampel kontrol, persentase sampel dengan asupan purin yang rendah $(76.9 \%)$ lebih tinggi daripada yang asupan purinnya tinggi $(23,1 \%)$.

Lemak merupakan zat gizi yang dibutuhkan oleh tubuh.Kebutuhan lemak normal adalah 2025 persen kebutuhan energi sehari. Konsumsi lemak yang berlebihan akan menghambat ekskresi asam urat melalui ginjal. lemak dapat juga meningkatkan resistensi insulin yang dapat mengakibatkan reabsorpsi asam urat di ginjal. ${ }^{21}$ Pada penelitian ini didapati sampel kasus yang memiliki asupan lemak kurang baik (> 25\% sehari) sebanyak 53,8 persen sedangkan pada sampel control hanya 25,6 persen. Hasil penelitian ini tidak sejalan dengan Budianti (2008) yang mendapatkan hubungan yang tidak bermakna dalam hubungan asupan lemak dan hiperurisemia. ${ }^{12}$

\section{SIMPULAN DAN SARAN}

\section{Simpulan}

Dari beberapa faktor yang diuji hubungan nya dengan hiperurinsemia, yang sangat tinggi risiko terkena hiperurinsemua adalah mereka dengan asupan cairan yang kurang dengan risiko 6,92 kali terkena hiperurisemia pada $95 \%$ Cl $(2,505$ - 19,112) dibandingkan dengan mereka dengan asupan cairan yang cukup. Riwayat hiperurisemia dalam keluarga adalah merupakan faktor resiko tertinggi kedua dimana dapat meningkakan risiko 6,379 kali terkena hiperurisemia pada 95\% Cl $(1,296$ - 31,411) dibandingkan yang tidak ada penderita hiperurisemia dalam keluarga.

Pada penelitian ini pula ternyata asupan purin yang tinggi akan meningkatkan risiko 3,889 kali terkena hiperurisemia pada $95 \% \mathrm{Cl}$ $(1,466$ - 10,313) dibandingkan asupan purin yang rendah. Untuk asupan lemak. Asupan purin yang tinggi, asupan lemak yang kurang dan riwayat hiperuresemia merupakan faktor perancu pada hubungan antara asupan cairan dan kejadian hiperurisemia.

\section{Saran}

Disarankan untuk penderita hiperurisemia untuk cukup mengkonsumsi cairan, agar ekskresi asam urat hasil metabolisme purin dari dalam tubuh dapat lebih cepat. Bagi para penderita hiperurisemia disarankan pula memilih dengan lebih selektif makanan dengan sumber purin rendah, seperti pembatasan sayuran warna hijau tua, makanan hasil laut, makanan/minuman hasil fermentasi. Selain itu, penderita hiperurisemia sebaiknya membatasi asupan makanan sumber lemak jenuh, seperti daging warna merah dan aneka gorengan. Khusus bagi penderita dengan riwayat keluarga hiperurisemia harus lebih berhati-hati dalam memilih makanan dan minuman sumber purin.

\section{RUJUKAN}

1. So A, Thorens B. Uric Acid Transport and Disease. The Journal Clinical Investigation. 2010; 120 (6):1791-1799.

2. Hensen-Tjokorda Raka Putra. HubunganKonsumsi Purin dengan Hiperurisemia Pada Suku Bali di Daerah Pariwisata Pedesaan. Jurnal Penyakit Dalam, 2007;8(1):37-43.

3. Lohsoonthorn V, Dhanamun B, Williams MA.., Prevalence of hyperuricemia and its relationship with metabolic syndrome in Thai Adults Receiving Annual health Exams. Archives of Medical Research, 2006;37 (7):883-889.

4. Nan H, Qiao Q, Dong Y, Gao W, Tang B, Qian $R$, et al. The Prevalence of Hyperuricemia in a Population of the coastal city of Qingdao China. The Journal of Rheumatology, 2006; 33(7):1346-1350.

5. Purwaningsih T. Faktor-faktor Risiko Hiperurisemia (Studi Kasus di Rumah Sakit Umum Kardinah Kota Tegal. Thesis. Semarang: Universitas Diponegoro, 2009..

6. Escott-Stump S. Nutrition and Diagnosis Related Care. Baltimore: Lippincott William \& Wilkins, 2008.

7. Santoso IB., Hardinsyah, Siregar P, Pardede SO. Air Bagi Kesehatan. Jakarta: Penerbit Centra Communications, 2011.

8. Almatsier S. Penuntun Diet. Jakarta: Gramedia Pustaka Utama, 2004 
9. Ilyas NO, Isdiany N. Ukuran Lingkar Pinggang dan Peningkatan Kadar Asam Urat Darah serta Faktor Lain yang Berpengaruh. Laporan Penelitian. Bandung: Poltekkes, 2006.

10. Aldona W. 2013.Hubungan Pola Konsumsi Bahan Makan Sumber Purin, Obesitas Sentral terhadap Kejadian Hiperurisemia pada Pasien Rawat jalan Poli Penyekit Dalam di Sumah Sakit Dustira Kota Cimahi: Karya Tulis IImiah.

11. Diantari E, Kusumastuti AC. Pengaruh Asupan Purin dan Cairan terhadap Kadar Asam Urat Wanita Usia 50-60 tahun di Kecamatan Gajah Mungkur Semarang.Journal of Nutrition College, 2013; 2 (1):12-18.

12. Budianti A.. Status Gizi dan Riwayat Kesehatan sebagai Determinan Hiperurisemia. Tesis. Bogor: Insitut Pertanian Bogor, 2008.

13. Johnson RJ, Kang DH, Feig D, Kivlighn S, Kanellis $\mathrm{J}$, Watanabe $\mathrm{S}$, et al. Is there a Pathogenetic Role for Uric Acid in Hypertension and cardiovascular and renal disease? Hypertention 2003;41(6):11831190 Hypertention 2003;41(6):1183-1190.
14. Lyu CL, Chi YH, Ching YY, Meei SL, Su HH, Ching $\mathrm{LCl}$. A case-control study of the association of diet and obesity with gout in Taiwan. American Journal of Clinical Nutrition, 2003; 78(4):690-701.

15. Rumah Sakit Angkatan Darat Cimahi. Laporan Tahunan Penyakit RSAD Dustira Cimahi Tahun 2012. Cimahi: RSAD Cimahi, 2012

16. Rahardjo JP, Tessy A. Batu Saluran Kencing, Jakarta: Balai Penerbit FKUI,1990.

17. Guyton AC. Fisiologi Kedokteran. Jakarta: EGC,1993.

18. Krause's. 2004. Food Nutrition and diet Theraphy. 1 th Edition. USA : Elsevier Sunder.

19. Thenawidjaja M. Principles of Biochemistry. Terjemahan. Jakarta: Penerbit Erlangga, 2008.

20. Hadian, Dadi. 2008. Faktor Risiko Penyekit Kardiovaskular. Pada tanggal 11 Desember 2011.

21. Wortman, RL. Gout dan Gangguan Metabolisme. .Jakarta: Penerbit Buku Kedokteran, 2000. 